\title{
A single administration of human umbilical cord blood $T$ cells produces long-lasting effects in the aging hippocampus
}

\author{
Md Shahaduzzaman • Jason E. Golden • Suzanne Green • \\ Allisun E. Gronda • Emanuelle Adrien • Aysha Ahmed • \\ Paul R. Sanberg • Paula C. Bickford • Carmelina Gemma • \\ Alison E. Willing
}

Received: 26 June 2012 / Accepted: 5 December 2012 / Published online: 22 December 2012

(C) The Author(s) 2012. This article is published with open access at Springerlink.com

\begin{abstract}
Neurogenesis occurs throughout life but significantly decreases with age. Human umbilical cord blood mononuclear cells (HUCB MNCs) have been shown to increase the proliferation of neural stem cells (NSCs) in the dentate gyrus (DG) of the hippocampus and the subgranular zone of aging rats (Bachstetter et al., BMC Neurosci 9:22, 2008), but it is unclear which fraction or combination
\end{abstract}

M. Shahaduzzaman · J. E. Golden • S. Green •

A. E. Gronda • E. Adrien • A. Ahmed - P. R. Sanberg •

P. C. Bickford · C. Gemma $\cdot$ A. E. Willing $(\bowtie)$

Center for Excellence in Aging and Brain Repair,

Department of Neurosurgery and Brain Repair,

Morsani College of Medicine, University of South Florida,

12901 Bruce B. Downs Blvd, MDC78,

Tampa, FL 33612, USA

e-mail: awilling@health.usf.edu

M. Shahaduzzaman

e-mail:mshahad@health.usf.edu

J. E. Golden

e-mail: jgolden@health.usf.edu

S. Green

e-mail: smgreen@ymail.com

P. R. Sanberg

e-mail: psanberg@health.usf.edu

P. C. Bickford

e-mail: pbickfor@health.edu

C. Gemma

e-mail: linella@mac.com

P. C. Bickford

Research Service, James A Haley VA Hospital,

13000 Bruce B Downs Blvd,

Tampa, FL 33620, USA of the HUCB MNCs are responsible for neurogenesis. To address this issue, we examined the ability of HUCB MNCs, CD4+, CD8+, CD3+, CD14+, and CD133+ subpopulations to increase proliferation of NSCs both in vitro and in vivo. NSCs were first grown in conditioned media generated from HUCB cultures, and survival and proliferation of NSC were determined with the fluorescein diacetate/propidium iodide and 5-bromo-2'-deoxyuridine incorporation assays, respectively. In a second study, we injected HUCB cells intravenously in young and aged Fisher 344 rats and examined proliferation in the DG at 1 week (study 2.1) and 2 weeks (study 2.2) postinjection. The effects of the HUCB MNC fractions on dendritic spine density and microglial activation were also assessed. HUCB T cells (CD3+, CD4+, and CD8+ cells) induced proliferation of NSCs $(p<0.001)$ and increased cell survival. In vivo, HUCB-derived CD4+ cells increased NSC proliferation at both 1 and 2 weeks while also enhancing the density of dendritic spines at 1 week and decreasing inflammation at 2 weeks postinjection. Collectively, these data indicate that a single injection of HUCB-derived $\mathrm{T}$ cells induces long-lasting effects and may therefore have tremendous potential to improve aging neurogenesis.

Keywords Cord blood cells · Aging · Proliferation

\section{Introduction}

Neurogenesis in the hippocampus continues throughout adult life primarily in two regions, the subventricular zone (SVZ) and subgranular zone (SGZ) in the 
hippocampal dentate gyrus (DG) (Emsley et al. 2005). With aging, there is hippocampal neurodegeneration (Gallagher et al. 1996), and although there is debate if there is a loss of quiescent early neural stem cells of type 1 or type B that are SOX1-positive cells, all studies reveal a loss of type III or type A migrating neuroblasts that are doublecortin/TUJ1 positive (Encinas et al. 2011; Hattiangady and Shetty 2008) and neural stem cells (NSCs) within the aforementioned neurogenic regions of adult brain (Maslov et al. 2004). Microglia are believed to regulate changes in hippocampal neurogenesis through the production of inflammatory mediators such as tumor necrosis factor alpha (TNF- $\alpha$ ) and interleukin-1 beta as well as the production of growth factors including insulin-like growth factor-1 and brain-derived neurotrophic factor (BDNF) (Ekdahl et al. 2003; Shetty et al. 2005; Gemma et al. 2010). Neuroinflammation has been shown to inhibit neurogenesis in the adult hippocampus and inflammatory blockade restores neurogenesis (Asahara and Kawamoto 2004).

Altered microglial function may not be the only determinant of changes in the inflammatory milieu of the brain and neurogenesis. Both the severe combined immunodeficiency mouse and the nude mouse have lower levels of neurogenesis compared to wild-type strain-matched mice, and this reduced neurogenesis is reversible with injection of splenic T cells (Antonchuk et al. 2002). Further, systemic depletion of the CD4+ $\mathrm{T}$ lymphocytes leads to significantly reduced hippocampal neurogenesis (ArienZakay et al. 2009). Administration of CD4+ but not CD8+ $\mathrm{T}$ cells in the $\mathrm{RAG}^{-/}$mice increased neurogenesis. These findings led us to suspect that human umbilical cord blood (HUCB) T cells may directly influence the proliferation of precursor cells in the SGZ and SVZ.

HUCB cells have shown therapeutic benefit by suppressing inflammation in the brain following stroke (Vendrame et al. 2005), and other neuroinflammatory conditions (Lee et al. 2012). The most compelling evidence comes from studies performed by our group in the rat permanent middle cerebral artery occlusion model of stroke. We have shown that HUCB cells decrease infiltration of monocytes, macrophage, and $\mathrm{B}$ cells into the stroked brain (Vendrame et al. 2005) and decrease microglial activation (Newcomb et al. 2006; Leonardo et al. 2010). These cellular changes are accompanied by decreased production of proinflammatory cytokines in the brain (Vendrame et al. 2005) and spleen and altered splenic $T$ cell function (Vendrame et al. 2006). Moreover, it was recently demonstrated that intravenous (i.v.) injection of the HUCB mononuclear cells (MNCs) enhances neurogenesis and decreases the number of activated microglia in the dentate gyrus of aging rats (Bachstetter et al. 2008). The HUCB MNC fraction is a heterogeneous population of cells composed of four major cell types: T cells, B cells, monocytes/macrophage, and stem cells. Boltze and colleagues (2012) recently reported that the $\mathrm{MNC}$ fraction had more neuroprotective effects than either the CD34+ or CD34- fractions in a rodent stroke model. The cellular component of the HUCB MNCs fraction responsible for the neuroprotective effect observed in the aging brain is still unknown. To this end, HUCB MNCs were fractionated into CD4+ T cells, CD8+ T cells, pan T cells (CD3+), CD14+ monocytes/macrophage, and CD133+ hematopoietic stem cell populations. In the first study, adult rat hippocampal NSCs were grown under proliferative conditions with the addition of HUCB-conditioned media to determine if the HUCB cell populations altered NSC proliferation (Fig. 1). In the second experiment, we first examined the ability of a single intravenous injection of the HUCB cells to alter proliferation in the DG of young or aged rats and quantified dendritic spine density in hippocampal CA1 pyramidal neurons during a short 1 -week survival. In the third experiment, we then extended the survival of the young and aged rats to determine if the HUCB cells produced long-lasting effects on proliferation in the DG and if this effect was accompanied by changes in inflammation.

\section{Methods}

Experiment 1. Effect of HUCB cells on adult NSCs in vitro

\section{Preparation of human umbilical cord blood cell-conditioned media}

Cryopreserved HUCB MNC fraction and its component subfractions $(\mathrm{CD} 3+, \mathrm{CD} 4+, \mathrm{CD} 8+, \mathrm{CD} 14+$, and CD133+) were obtained from AllCells, LLC. HUCB cells were thawed in a $37^{\circ} \mathrm{C}$ water bath for $1 \mathrm{~min}$ and then washed twice in $10 \mathrm{ml}$ phosphate-buffered saline (PBS)/100 $\mu$ l DNase (Sigma \#D4527-40KU, $1 \mathrm{mg} /$ $\mathrm{ml})$. HUCB cells were then grown in Neurobasal media at a density of $10^{5} / \mathrm{cm}^{2}$ in a 24-well plate and incubated at $37{ }^{\circ} \mathrm{C}$ in a $5 \% \mathrm{CO}_{2}$-humidified incubator. Sample media $(500 \mu \mathrm{l})$ were collected every other day 
for 6 days and stored at $-80{ }^{\circ} \mathrm{C}$ until needed. Conditioned media collected on day 2 were used for the subsequent experiments.

\section{Rat neural stem cell preparation}

Adult rat hippocampal NSCs (Chemicon, Cat \#SCR022) were grown in NSC Expansion Media (Chemicon Cat \#SCM009) at a density of $10^{5}$ cells $/ \mathrm{cm}^{2}$ on poly-L-ornithine and laminin-coated T75 tissue culture flasks. The cells were passaged at $80 \%$ confluence, frozen at $-80^{\circ}$ $\mathrm{C}$, and cryogenically preserved in liquid nitrogen. Once we had a stock of NSCs, the NSCs were plated at the density of $2.5 \times 10^{5}$ cells $/ \mathrm{cm}^{2}$ in NSC Expansion Media $(200 \mu \mathrm{l})$ supplemented with B27, $2 \mathrm{mML}$-glutamine and $1 \times$ solution of penicillin, streptomycin, and Fungizone on a poly-L-ornithine and laminin-coated $96-$ well tissue culture plate. The cells were incubated at $37{ }^{\circ} \mathrm{C}$ in a $5 \%$ $\mathrm{CO}_{2}$-humidified incubator. After $24 \mathrm{~h}$, the HUCBconditioned media were added at a ratio of $50 \%$ Neurobasal media and $50 \%$ HUCB-conditioned media. The culture was treated with fresh conditioned media every other day during a 6-day period. FGF-2 (20 ng/ $\mathrm{ml}$ ) was also added at each media change. Conditioned media collected on day 2 were utilized for the analysis.
Fluoroscein diacetate/propidium iodide viability staining

Cell viability was determined using the fluoroscein diacetate/propidium iodide (FDA/PI) assay. The assay mixture was made by adding $5 \mu$ l of FDA stock ( $5 \mathrm{mg} /$ $\mathrm{ml}$ in acetone, Invitrogen \#F1303) solution and $2 \mu \mathrm{l}$ of PI working solution (.02 mg/ml, Invitrogen \#P1304MP) in $500 \mu \mathrm{l}$ of PBS. The mixture was added to each well and incubated at $4{ }^{\circ} \mathrm{C}$ for $5 \mathrm{~min}$. The cultures were then photographed under a fluorescent microscope (Olympus inverted microscope IX71). For each culture, ten pictures were taken at random, and five of the ten were chosen randomly for analysis. The number of living (FDA positive, green) and dead (PI positive, red) cells were counted manually using ImagePro-II software.

\section{5-Bromo-2'-deoxyuridine incorporation into proliferating cells in vitro}

On day $6,20 \mu \mathrm{l}$ of 5-bromo-2'-deoxyuridine (BrdU) (1:2,000, Calbiochem \#QIA58) was added into each well. The BrdU was allowed to incubate with the cells for $2 \mathrm{~h}$ in tissue culture. Cultures were then washed three times with $1 \times \mathrm{PBS}$ and denatured in $2 \mathrm{~N} \mathrm{HCl}$
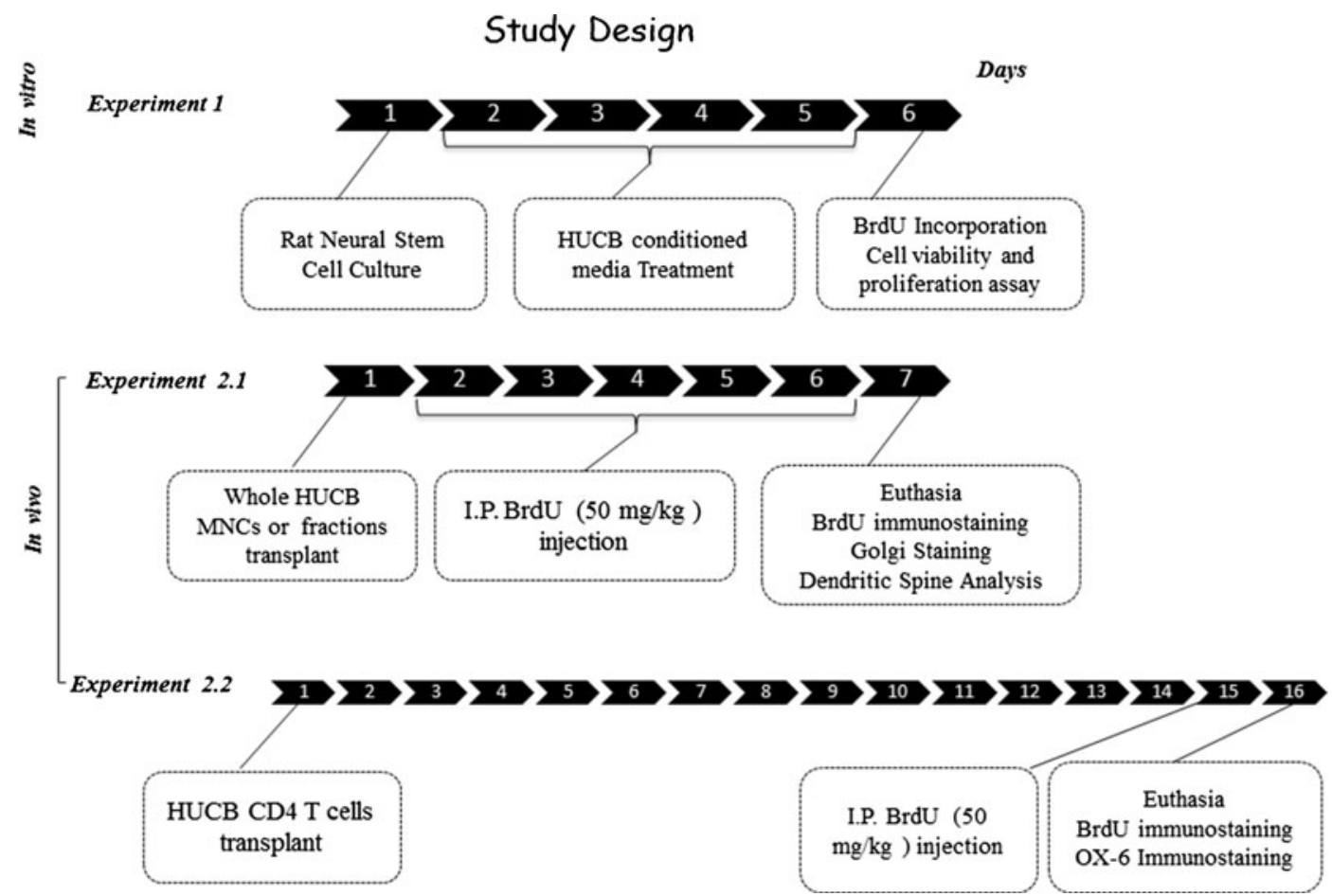

Fig. 1 A schematic diagram depicting experimental groups and study design in the present study 
two times for $15 \mathrm{~min}$ at $60{ }^{\circ} \mathrm{C}$. Following this, the cultures were incubated in a neutralizing solution

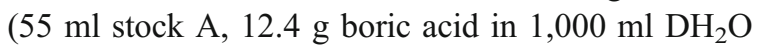
$+45 \mathrm{ml}$ Stock B, $19 \mathrm{~g}$ sodium borate in $1,000 \mathrm{ml}$ $\mathrm{DH}_{2} \mathrm{O}$ at $\mathrm{pH}$ 8.5) two times for $15 \mathrm{~min}$. Cells were then washed in PBS three times. After 1-h blocking (870 $\mu \mathrm{l}$ PBS, $30 \mu \mathrm{l} 10 \times$ Triton, $100 \mu \mathrm{l}$ normal goat serum (NGS)), the cultures were then incubated overnight in rat anti-BrdU antibody (1:500, Accurate Chemicals \#OBT0030). On the next day, the cells were washed three times in $1 \times$ PBS and incubated in the secondary antibody (Alexa Fluor goat anti-rat 594, Invitrogen, \#A11007, 1:1,000), for $1 \mathrm{~h}$ at room temperature. Finally, the cultures were washed three times in $1 \times$ PBS and pictures were taken with a fluorescent microscope (Olympus inverted microscope IX71). For each culture, ten pictures were taken, moving in a clockwise circle around the well. Then, five of those ten were chosen randomly for analysis. The cells were counted manually using ImagePro-II software. The data are expressed as a mean \pm SEM.

Experiment 2. Effect of HUCB cells on hippocampal cell proliferation in the aged brain

\section{Experiment 2.1. Effect of HUCB cells on proliferation and dendritic growth in the hippocampus of aged rats 1 week after administration}

Animals Male Fisher 344 rats (Harlan) used in this study were grouped into two categories: young adult (4 months old) and aging (24 months old). All experiments were conducted in accordance with the National Institute of Health policy guidelines. Animal protocols were reviewed and approved by the Institutional Animal Care and Use Committee. All animals were pair-housed under a 12-h light/dark cycle and had access to water and food ad libitum. Rats were randomly assigned ( $n=$ 10/group) to either (1) young adult + media (control), (2) young adult+HUCB MNC (whole), (3) aging+media (control), (4) aging + HUCB MNC (whole), (5) aging+ CD4+ cells, (6) aging + CD8 + cells, (7) aging + CD14+ cells, or (8) aging + CD133+ cells.

HUCB cell transplantation Rats were placed in a supine position and anesthetized with isoflurane (2-5\% at $2 \mathrm{~L} \mathrm{O}_{2} / \mathrm{min}$ ). After wiping with $70 \%$ ethanol, the penile vein was exposed by withdrawing the penis from within its protective sheath. The HUCB cell fractions were delivered into the penile vein by inserting the 23-gauge needle into the lumen of the vein and slowly delivering the cells in a volume of $500 \mu \mathrm{l}$ of PBS. The needle was withdrawn slowly and pressure applied to minimize bleeding, usually about $30 \mathrm{~s}$. The same volume of PBS without cells was also delivered as a control treatment.

Preparation of HUCB MNC subpopulations for transplantation The frozen HUCB MNCs were obtained from AllCells, LLC (Emeryville, CA, USA), (CD4+: CB020-2 F, CD8+: CB020-3 F, CD14+: CB022F, whole HUCB MNC: CB00-3 F, CD133+: CB013F). Cryopreserved HUCB cells were thawed and washed in $10 \mathrm{ml}$ PBS $+100 \mu \mathrm{l}$ DNase (Sigma \#D4527-40KU, $1 \mathrm{mg} / \mathrm{ml}$ ). Cell viability was determined using the Trypan Blue exclusion method and ranged from 80 to $90 \%$. The number of cells to be injected was determined based on the percentage of the whole HUCB MNC that is composed of each cell type and a standard transplant dose of $10^{6}$ viable cells/ $500 \mu$ l. In our previous study of proliferation in the aging hippocampus with the MNC (Bachstetter et al. 2008), these cells were effective in inducing proliferation at these doses when delivered in combination (i.e., the whole MNC). To alter the dose of the individual cells such that all cells were delivered at $10^{6}$ would have also been problematic, since there are dose-dependent effects of cell delivery and too many cells can have detrimental effects (Vendrame et al. 2004; Garbuzova-Davis et al. 2012). Therefore, $4.8 \times$ $10^{5}$ cells were injected in the CD4+ group, $1.3 \times 10^{5}$ in the $\mathrm{CD} 8+$ group, $1.4 \times 10^{5}$ in the $\mathrm{CD} 14+$ group, $0.2 \times$ $10^{5}$ in the $\mathrm{CD} 133+$ group, and $1 \times 10^{6}$ in the HUCB MNC group. Rats were then anesthetized with isoflurane and randomly assigned to treatment group.

BrdU incorporation in vivo Young adult and aged Fisher 344 rats were injected intraperitoneally, once daily for 5 days, with BrdU $(50 \mathrm{mg} / \mathrm{kg}$, SigmaAldrich, St. Louis, MO) beginning $24 \mathrm{~h}$ after transplantation. Animals were euthanized $24 \mathrm{~h}$ after the last BrdU injection and transcardially perfused with phosphate buffer, followed by $4 \%$ paraformaldehyde (PFA). The brains were removed, postfixed in the same $4 \%$ PFA for $24 \mathrm{~h}$, and then placed in $20 \%$ sucrose for $24 \mathrm{~h}$. Brains were cut into $30-\mu \mathrm{m}$ sections in the coronal plane using a Micro cryostat (RichardAllan Scientific) and stored at $-20{ }^{\circ} \mathrm{C}$ in cryoprotectant solution. 
BrdU immunostaining All histochemical staining was conducted on free-floating sections. Following extensive washes in PBS, sections were incubated two times in $2 \mathrm{~N} \mathrm{HCl}$ for $30 \mathrm{~min}$ at $65^{\circ} \mathrm{C}$ and neutralized by immersion twice for $15 \mathrm{~min}$ in neutralizing solution as described for the culture studies. Several rinses in PBS were followed by incubation in $10 \%$ NGS blocking solution for $1 \mathrm{~h}$ and then incubated overnight in rat anti-BrdU antibody (1:500, Accurate Chemicals \#OBT0030) at $4{ }^{\circ} \mathrm{C}$. The following day, sections were washed, incubated for $1 \mathrm{~h}$ in biotinylated goat anti-rat secondary antibody (Alexa Fluor goat anti-rat 594, Invitrogen, \#A11007, 1:200, Invitrogen \#A11006), and then washed three times in PBS for $10 \mathrm{~min}$ before a 1-h incubation in avidin-biotin complex (ABC kit, Vector Laboratories). After being washed in PBS, sections were incubated in 3,3'-diaminobenzidine (DAB) solution and visually inspected under a microscope to assess the degree of color development for 1 to $3 \mathrm{~min}$. The sections were washed three times in PBS for $10 \mathrm{~min}$ when the DAB staining reaction was completed. Sections were then mounted on slides and dried completely. The slides were then dehydrated through an ethanol series (3 $\mathrm{min}$ in $50 \%$ ethanol, $3 \mathrm{~min}$ in $70 \%$ ethanol, $3 \mathrm{~min}$ in $95 \%$ ethanol, $3 \mathrm{~min}$ in $100 \%$ ethanol) before being cleared in xylene and coverslipped with DPX mountant.

Stereological quantification of BrdU-labeled proliferating cells The optical fractionation method of unbiased stereological cell counting as described by Williams and Rakic (1988) was used to count BrdU+ cells in the entire dentate gyrus including the subgranular zone. This method, commonly used in neuroscience, provides an estimate of cell numbers that are uninfluenced by the size, shape, spatial orientation, and spatial distribution of the cells (West and Gundersen 1990). Every sixth section $(240 \mu \mathrm{m}$ apart) from each animal ( $n=8$ /group) was processed for BrdU immunohistochemistry. Using Stereo Investigator software (MBF Bioscience), an outline of the anatomical structure was produced under $\times 4$ magnification and cell quantification was conducted at $\times 40$ magnification. In order to count the BrdU+ cells, the grid size was set at $125 \times 125 \mu \mathrm{m}$ and the counting frame was set at $250 \times 250 \mu \mathrm{m}$. BrdU+ cells that intersected the uppermost focal plane (exclusion plane) or the lateral exclusion boundaries of the counting frame were not counted.
Golgi staining and dendritic spine analysis Aging is associated with a decline in cognitive function, and a common misconception about brain aging is that cognitive decline could result from a considerable loss of neurons. However, it has been demonstrated that aging results in a significant decline in the number of the dendritic spines (Asahara and Kawamoto 2004) and region-specific changes in dendritic branching and spine density are more characteristic of the effect of aging on neuronal morphology (Burke and Barnes 2006). Chen and colleagues (2010) examined the effects of HUCB MNCs on survival, proliferation, and dendritic arborization of adult hippocampal neurons harvested from both young and aged rats. The authors found that HUCB MNCs were able to protect hippocampal neurons in vitro and promote the growth of dendrites principally at the level of secondary and tertiary dendritic branches.

Two rats from each group $(n=16)$ were processed for Golgi staining. After perfusion, the brains were quickly and carefully removed and cut into blocks of $10 \mathrm{~mm}$ in thickness and processed according to the manufacturer's specifications using the Rapid GolgiStain ${ }^{\mathrm{TM}} \mathrm{Kit}$ (FdPK401, MTR Scientific, LLC). The sections were first immersed in an impregnation solution (equal parts of solutions $\mathrm{A}$ and B) for 2 weeks in the dark at room temperature, replacing solutions after the first $6 \mathrm{~h}$. The tissue was then placed in solution $\mathrm{C}$ for $48 \mathrm{~h}$ in the dark at $4{ }^{\circ} \mathrm{C}$, again replacing the solution after $24 \mathrm{~h}$. Coronal tissue sections were then cut on a cryostat and mounted on gelatinized glass slides. Sections were dehydrated in 50,75 , and $95 \%$ ethanol for 4 min each followed by four rinses in absolute ethanol (4 min each) before being cleared in xylene three times for 4 min each and coverslipped with Permount. For dendritic spine analysis, hippocampal CA1 pyramidal neurons were randomly selected that met the following criteria: (1) their branches and spines were fully impregnated, (2) consistent and dark impregnation along the entire dendritic field, and (3) relative isolation from neighboring impregnated neurons to avoid overlap. Dendritic spines from the selected neurons were evaluated and counted by a single blind rater using an Olympus BX60 microscope with a $\times 100$ oil immersion objective lens. Starting from the origin of the branch and continuing away from the cell soma, spines were counted along a $30-\mu \mathrm{m}$ stretch of the dendrite. Only dendritic segments that appeared both generally linear and parallel to the optical plane were selected. Spines were quantified in terms of 
spine density (number of spines/30- $\mu \mathrm{m}$ segments). Three or four uncut terminal tip segments from the basilar tree of each of the CA1 pyramidal cells were selected for spine counting (Fig. 2). For the entire study, a total of 18 brains were analyzed; spines were counted from 42 neurons and along 360 basilar terminal tips (20 terminal dendritic tips per animal). The rationale for our protocol was based on a survey of the recent literature using Golgi staining and dendritic spine analysis in the hippocampus (Morgenstern et al. 2008; Adlard et al. 2011; Chapleau et al. 2012; Huang et al. 2012).

\section{Experiment 2.2. Effect of HUCB cells on proliferation} and inflammation in the hippocampus of aged rats 2 weeks after administration

Animals Aged male Fisher 344 rats (22 months of age, Harlan) were randomly assigned to either PBS $(n=5)$ or CD4+ HUCB cell injection $(n=9)$. Young Fisher 344 rats $(3$ months of age, $n=5)$ treated with media were also used as controls.
HUCB cell transplantation The frozen CD4+ HUCB MNCs were prepared and transplanted as described in experiment 2.1 .

BrdU incorporation in vivo On day 15, 2 weeks after HUCB injection, the rats were treated with BrdU $(50 \mathrm{mg} / \mathrm{kg})$ twice a day at 9-h intervals. On day 16 , the rats were euthanized and were perfused with $4 \%$ PFA. The brains were removed, postfixed in the same $4 \%$ PFA for $24 \mathrm{~h}$, and then placed in $20 \%$ sucrose for $24 \mathrm{~h}$. Brains were cut into $40-\mu \mathrm{m}$ sections sagitally through half of the brain. Immunohistochemistry to identify the BrdU-labeled cells ( $n=5 /$ group) was performed as described in experiment 2.1 .

OX-6 immunostaining procedure For OX-6 immunohistochemistry, free-floating sections were incubated overnight with mouse anti-rat OX-6 (Pharmingen, San Diego, CA; 1:750); all other steps were the same as described for the BrdU immunohistochemistry. In order to count the OX-6+ cells in aged vehicle- and CD4-treated rats, the grid size was set at $50 \times 50 \mu \mathrm{m}$

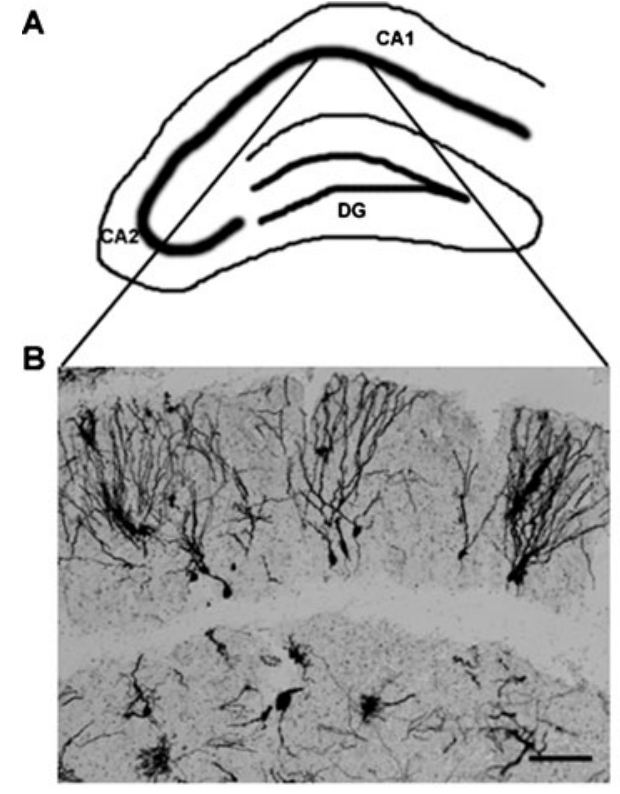

Fig. 2 Schematic representations of dendritic spine counting experiment. a Graphical representation of the location of hippocampal CA1 pyramidal neurons. b Hippocampal pyramidal neurons were initially observed at the light microscopic level using an Olympus BX60 microscope with a $\times 20$ objective. c

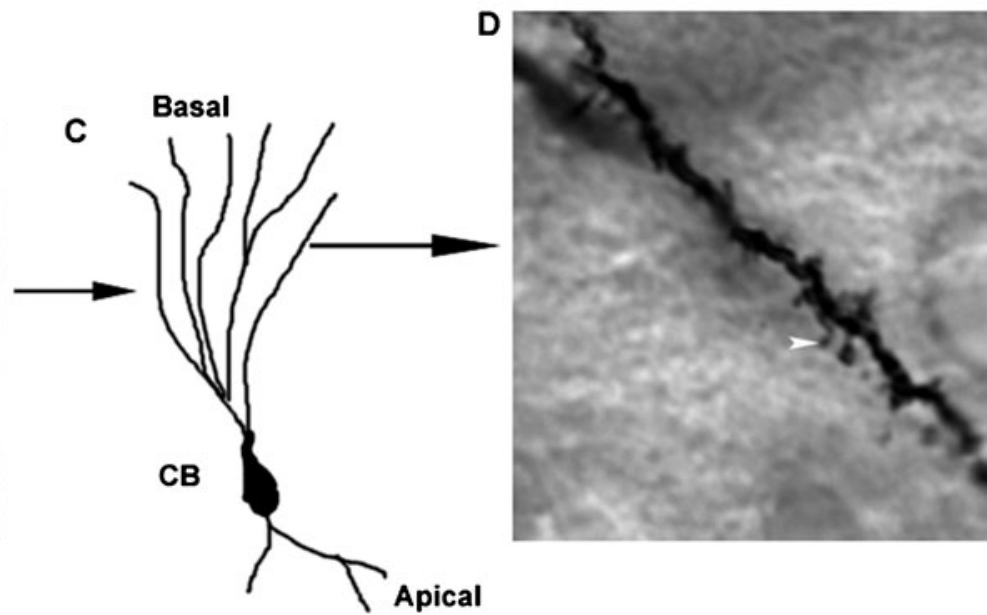

Schematic representation of a pyramidal neuron and its basal dendrites located in the dorsal part of CA1. d Dendritic spines from selected neurons were counted with a $\times 100$ oil immersion objective lens. Scale bar $=100 \mu \mathrm{m}$ 
and the counting frame was set at $150 \times 150 \mu \mathrm{m}$. At least 250 cells were counted per animal. Outlines of the SGZ in the hippocampus were drawn using the $\times 2$ objective when counting OX-6+ cells. The actual counting of the cells was performed at $\times 60$ magnification, and OX-6+ cells were counted in the entire dentate gyrus including the SGZ of the hippocampus.

\section{Statistical analyses}

Data are expressed as means \pm SEM. The data in experiment 1 were not normally distributed and were therefore analyzed using the Kruskal-Wallis test followed by Dunn's multiple comparison tests. Based on the results of experiment 1, we made a priori comparisons using Student's $t$ tests for the BrdU incorporation assay measuring proliferation in experiments 2.1 and 2.2. Our hypotheses were that the aged media-treated rats would have significantly less BrdU labeling of cells in the dentate gyrus than young media-treated animals and significantly less BrdU labeling than the $\mathrm{T}$ cell-treated rats. We did not have any a priori hypothesis for the Golgi or OX-6 data. The Golgi data were nonparametric and were analyzed using the Kruskal-Wallis test followed by Dunn's multiple comparison tests. The OX-6 data were parametric and were analyzed with the Student's $t$ test. All statistical analyses were performed using Prism software version 5.0 (GraphPad).

\section{Results}

Experiment 1. Cord blood cells increased survival and proliferation of adult rat hippocampal NSCs in vitro

In order to identify the specific fractions of the HUCB MNCs responsible for the increased survival of the adult rat hippocampal NSC, we cultured NSCs in conditioned media from HUCB MNC, CD2+ (pan or all $\mathrm{T}$ cells), $\mathrm{CD} 4+\mathrm{T}$ cells, CD8 $+\mathrm{T}$ cells, CD14+ monocytes, or CD133+ stem cells. Cell viability was determined with the FDA/PI assay. The cells were counted in five fields from each replicate and at least two replicates per condition were used. In the NSC only group, cell viability (percentage of living cells) was $67.97 \pm 5.26 \%$ (Fig. 3a, g). Viability of the HUCB $\mathrm{MNC}$ group was not significantly different from the untreated NSC (66.12 $\pm 4.80 \%$, Figs. $2 b$ and $3 g)$. Only in groups conditioned with pan T cell $(87.63 \pm 2.20 \%$, Fig. 3 g) and CD8+ cell $(87.96 \pm 2.65 \%$, Fig. 3f, g) were there statistically significant increases in cell viability compared to the MNC group $(p<0.05)$. In contrast, NSC cultures treated with media from CD14+ $(49.56 \pm$ $9.00 \%$, Fig. 3b) and CD133+ (37.96 $7.9 \%$, Fig. 3d) HUCB cells had significantly fewer cells than pan T- and CD8-treated cultures $(p<0.001)$.

NSC proliferation was measured using the BrdU incorporation assay. NSCs that were grown in untreated culture media proliferated slowly as demonstrated by the few BrdU-labeled cells in the culture (Fig. 4a). When the NSCs were grown in conditioned media from the whole HUCB MNC fraction (Fig. 4b), CD14+ cells (Fig. 4c), or CD133+ cells (Fig. 4d), there appeared to be more BrdU+ cells relative to the untreated group. In those cultures exposed to HUCB T cells, BrdU was incorporated into many of the cells in culture (Fig. $4 \mathrm{e}-\mathrm{f}$ ). When we quantified the number of BrdU+ cells in each of the experimental conditions, only in the $\mathrm{T}$ cell-conditioned cultures were there significant increases in BrdU incorporation compared to the untreated culture (CD4+ - conditioned, 299.6+71.5 cells/field; CD8+ - conditioned 244.6+65.0; pan Tconditioned, 264.9+75.9; compared to untreated 19.4+ $4.1 ; p<0.001$ ) (Fig. 4g).

Experiment 2.1. Cord blood cells restored proliferation and dendritic growth in the hippocampus of aged rats 1 week after administration

We have shown that HUCB cells administered i.v. induce proliferation in the SGZ of the aged rat (Bachstetter et al. 2008). To determine which specific fractions of HUCB MNCs contribute to this induced proliferative response, young adult and aged rats were injected with either MNC, CD4+, CD8+, CD14+, or CD133+ HUCB cells. BrdU was then injected on a daily basis for 5 days to label the proliferating cells beginning $24 \mathrm{~h}$ after transplantation. Quantifying the number of BrdU+ cells in the SGZ/GCL using the optical fractionator method of stereology, we found that BrdU-labeled cells were predominantly detected in the SGZ of DG both in young adult and aged rats. There were clusters of BrdU+ cells in the DG, especially in the HUCB MNC-treated rats compared to the media-treated controls (Figs. 5b and 6). When we quantified the number of BrdU+ cells in the DG, we found that there were significantly more $(964 \pm 275)$ 

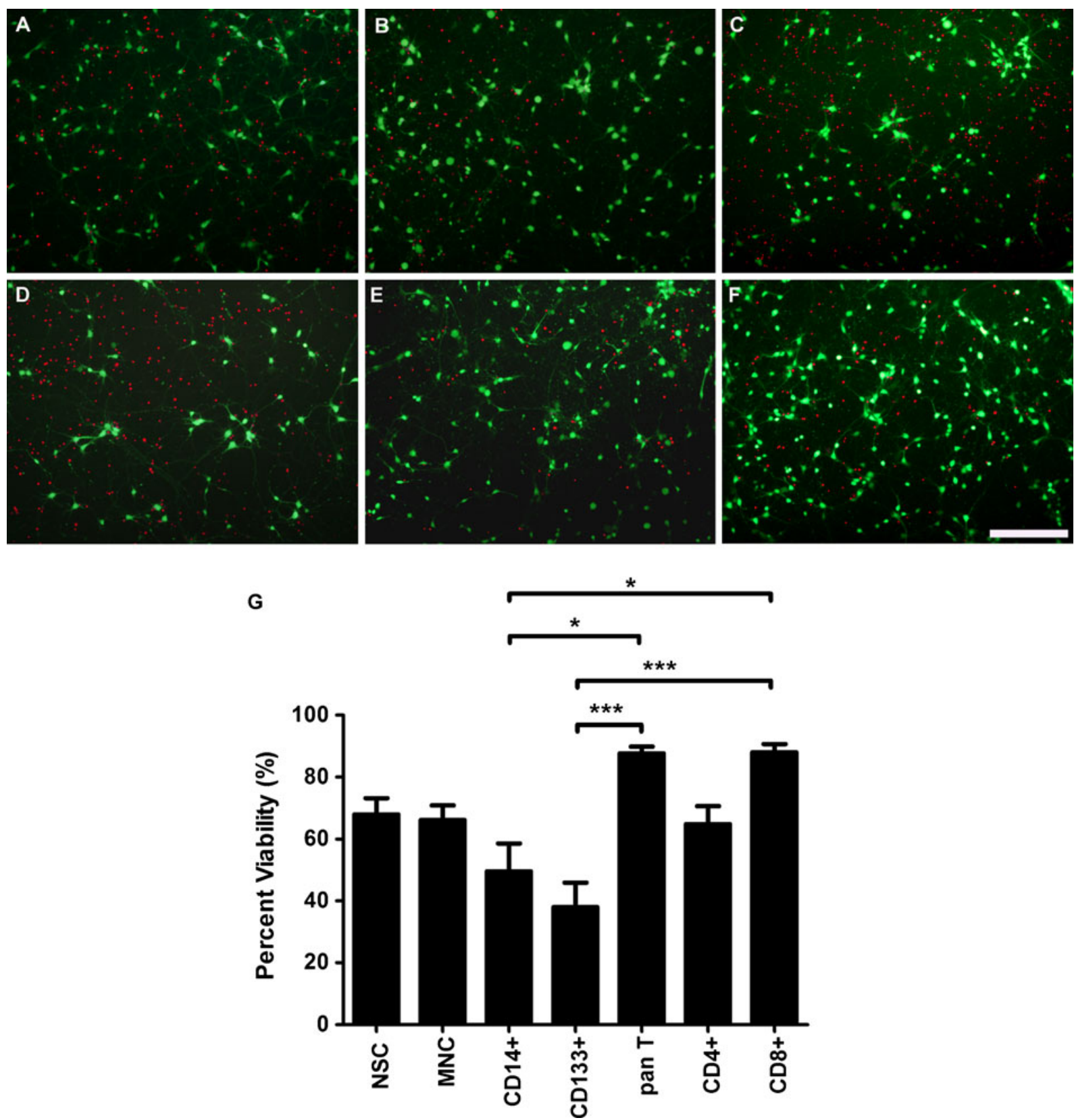

Fig. 3 HUCB-conditioned media improves rat hippocampal NSC survival in culture. NSCs were cultured in HUCBconditioned media or left untreated. Dilutions of conditioned media (1:2) were added to cultures of rat adult hippocampal NSCs. Photographs depict double labeling of cultures with FDA (green, live) and PI (red, dead). a NSC cells alone or cultured in conditioned media from HUCB MNC (b), CD14+ (c), CD133+

BrdU+ cells in the young adult media-treated rats compared with the aged media-treated rats $(483 \pm 80$, $p<0.05)$. In aged animals injected with CD4+ HUCB (d), CD4+ (e), and CD8+ (f). g Percent survival of NSC after treatment with conditioned media. NSC survival was significantly increased in cultures treated with condition media from HUCB CD8+ cells compared to HUCB-derived CD14 and CD133. ${ }^{*} p<0.05$ and $* * * p<0.001$, significant differences. Scale bar $=100 \mu \mathrm{m}$

cells, there was a significant increase $(938 \pm 182)$ in BrdU+ cells compared to the aged rats that received media alone $(483 \pm 80, p<0.05)$, returning the number 

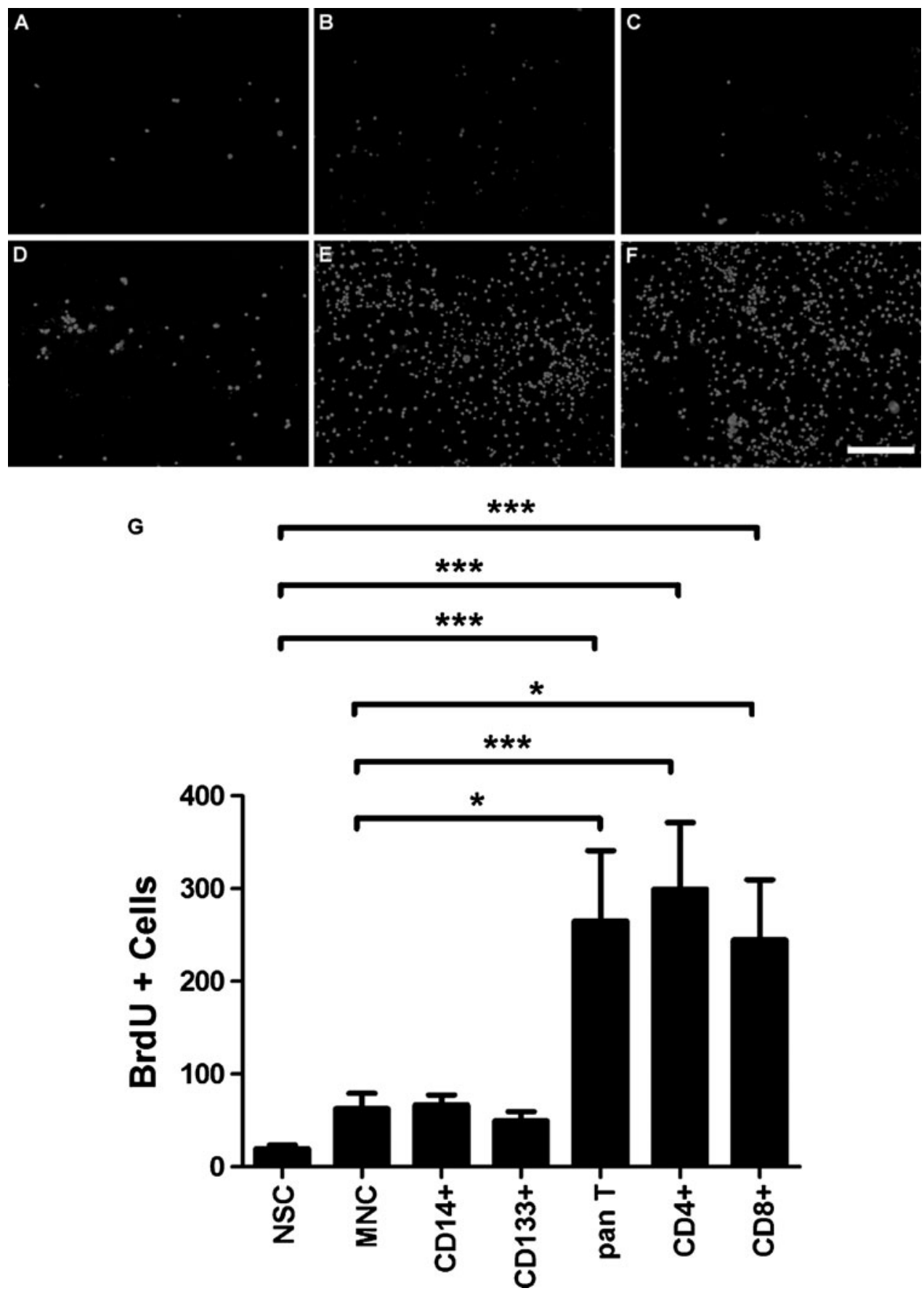

Fig. 4 Effect of HUCB-derived condition media on NSC proliferation in vitro. NSC cells were grown for 6 days in HUCBconditioned media and treated with BrdU for $2 \mathrm{~h}$ prior to fixation. Immunocytochemistry was used to identify BrdU+ cells for counting. a BrdU labeling of untreated NSC is minimal. Addition of media conditioned with HUCB MNC (b), CD14 (c), and CD133 (d) had little effect on BrdU incorporation. When NSCs were treated with media conditioned with CD4 (e) and CD8 (f), there were substantially more BrdU-labeled cells in culture. $g$ The percentage of total NSC cells that was BrdU positive after treatment with conditioned media. A significant increase in BrdU+ cells was observed when the NSCs were grown in media conditioned with HUCB T cell (pan T, CD4, and CD8) when compared to NSC grown alone. There were no significant increases in the number of BrdU+ cells when the NSCs were grown in conditioned media from HUCB MNC, CD14, and CD133 as compared to NSC grown alone. Scale bar $=100 \mu \mathrm{m}$ 
Fig. 5 In vivo BrdU labeling in the DG 1 week after HUCB transplantation. Photomicrographs of BrdU+ cells (dark brown) in the sections from young mediatreated rats (a) or HUCB MNC-treated (b) and from old rats treated with media (c), HUCB MNC (d), CD14 (e), CD4 (g), and CD8 (h). $\mathrm{BrdU}(50 \mathrm{mg} / \mathrm{kg}$ ) was administered once daily for 5 days beginning $24 \mathrm{~h}$ after HUCB administration. More BrdU+ cells were observed in aged rats treated with CD4+ cells and in young rats treated with HUCB MNC cells compared to control counterparts. Scale bar $=50 \mu \mathrm{m}$
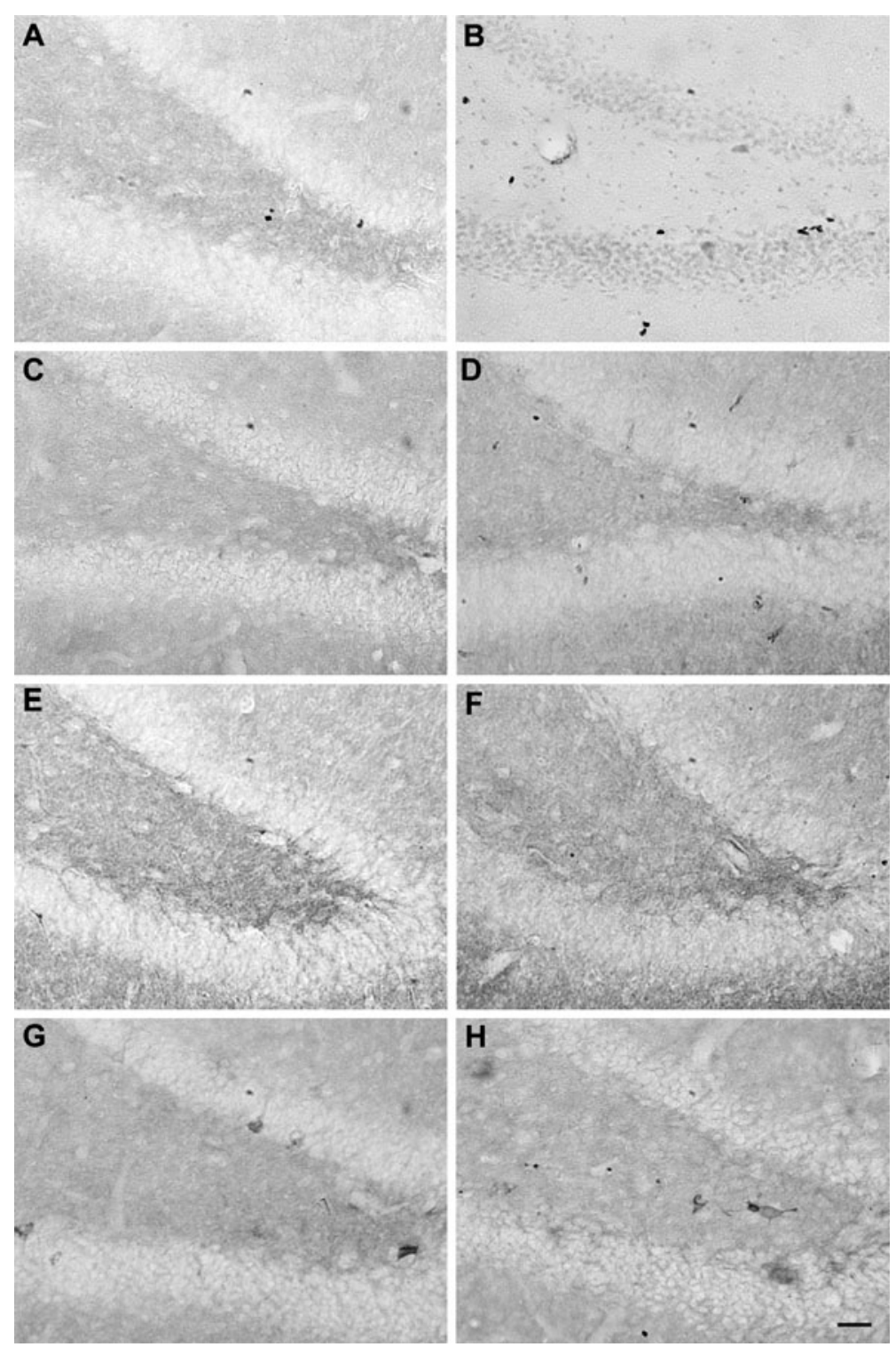

of BrdU+ cells in the aged animals to the level observed in the young controls. The CD8+ T cells did not have the same effect $(598 \pm 99)$.

To examine in more detail whether i.v. injection of HUCB cells has any effect on the dendritic morphology of neurons in the hippocampus, brain sections were processed with Golgi and the number of dendritic spines on the stained dendrites was quantified (see Fig. 2 for a graphical representation of the procedure). There appeared to be a decrease in the density of dendritic branches with age (Fig. 7). In the overall analysis, there were significant group differences using the Kruskal-Wallis test $(p<0.0001$, Fig. 8). The young rats treated with media had greater spine density $(0.43 \pm .002)$ compared to the aged media-treated rats $(0.32 \pm 0.01, p<0.001)$. Treating the young rat with MNC did not alter spine density $(0.48 \pm 0.02)$ from the level observed in the young media-treated group; however, the aged rats treated with HUCB MNCs had significantly more spines per length of dendrite $(0.45 \pm 0.02)$ than aged media-treated rats $(0.32 \pm 0.01, p<0.001)$ as did the groups treated with $\mathrm{CD} 4+(0.47 \pm 0.02)$ and $\mathrm{CD} 8+(0.49 \pm 0.02)$ as well $(p$ $<0.001)$. In the aged MNC, CD4- and CD8-treated animals' spine density returned to the level observed in the young adult brain. The other cord blood 


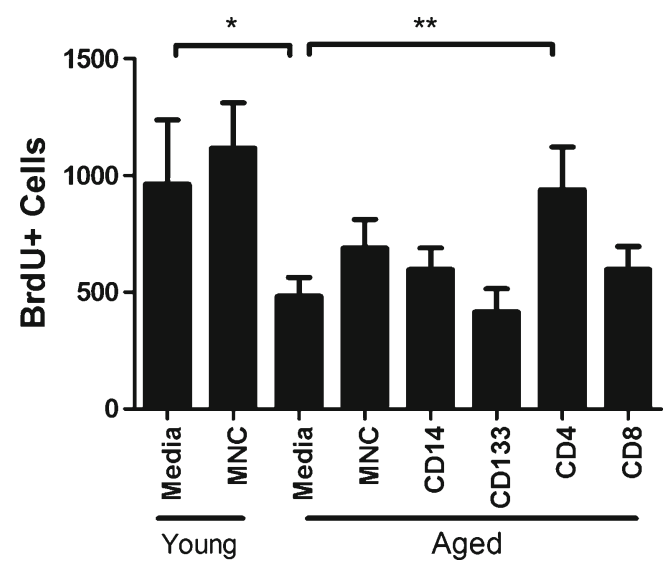

Fig. 6 Quantitative analysis of BrdU+ cells in the SGZ. Significantly more BrdU+ cells were observed for the aged groups treated with CD4+ HUCB cells compared to the corresponding aged media-treated groups. ${ }^{*} p<0.05,{ }^{* *} p<0.01$

fractions $(\mathrm{CD} 14+(0.28 \pm 0.01)$ and $\mathrm{CD} 133+(0.30 \pm$ $0.01)$ ) did not increase spine density compared to the aged media-treated rats.

Experiment 2.2. CD4+ HUCB cells induced longlasting proliferation of hippocampal cells

The objective of this study was to determine if the effect of HUCB administration would be maintained beyond the initial week after injection. When the aged rats were injected with BrdU 14 days after a single penile vein transplantation of CD4+ T cells, we found that there was a significant increase in the number of BrdU+ cells in the DG $(2,585 \pm 251, p<0.05$, Fig. 9) compared to aged media-treated animals $(1,705 \pm 74)$ using the optical fractionator method of stereology. Here, we used young media-treated rats as a control; they had a similar number of BrdU+ cells $(2,804 \pm$ 305 ) as was observed in aged rats treated with CD4+ cells.

To determine if CD4+ $\mathrm{T}$ cell treatment affected hippocampal neurogenesis by decreasing inflammation in the aged brain, microglial activation was quantified in the hippocampus of the aged rat brain treated either with media or CD4+ HUCB cells. As seen in Fig. 10, OX-6+ microglia were visible in the hippocampus of aged rats, but few were observed in the hippocampus of rats treated with CD4+ cells. The OX6-stained cells exhibited numerous short processes with enlarged cell bodies, which was consistent with the activated microglial morphology. When the total number of OX-6 immunoreactive activated microglia in the hippocampal formation was counted using the optical fractionator method of unbiased stereology, we found that aged media-treated rats had many OX-6+ microglia $(35,023 \pm 649)$. In contrast, aged rats treated with CD4+ cells had significantly fewer OX-6+ microglia $(25,990 \pm 1,148, p<0.001)$.

\section{Discussion}

The goal of our present study was to determine which HUCB subpopulation is responsible for the neurogenic and protective effects of HUCB cells in the adult hippocampus and to explain how HUCB subpopulations then act on progenitor cells to increase neurogenesis. In the first study, we demonstrated that HUCB-derived T cells increase survival and proliferation of adult neural stem cells in vitro. In the second experiment, we showed that $\mathrm{CD} 4+\mathrm{T}$ cells isolated from HUCB significantly promoted proliferation of NSCs in the DG of aging rats and restored dendritic spine density of the hippocampal CA1 pyramidal cells at 1 week postinjection. In experiment 3, we demonstrated that a single penile vein injection of HUCB $\mathrm{CD} 4+\mathrm{T}$ cells in aged rats produces sustained increases in proliferation in the DG and also decreases the amount of activated microglia in the aged rat brain. These results suggest that HUCB T cells may provide trophic support to these aging neurons thereby enhancing proliferation and maintaining dendritic and axonal connections in the aging brain.

HUCB MNC cells have been shown to increase proliferation within the hippocampus of the aging rat (Bachstetter et al. 2008). It has been reported that neurogenesis in the SGZ and SVZ significantly decreases in the $\mathrm{T}$ cell-deficient mice (Romero et al. 2002). In addition, the lack of $T$ cells was found to primarily affect the proliferative capacity of neural progenitor cells in their niches, and this proliferative capacity was partially restored by injecting splenocytes into immune-deficient mice ( $\mathrm{Ziv}$ et al. 2006). Wolf et al. (2009) recently showed that systemic depletion of CD4+ T cells leads to a decrease in cell proliferation in the DG whereas the absence of $\mathrm{B}$ cells had no effect. They further demonstrated that proliferation was increased by the introduction of donor CD4+ cells. This restoration of normal neurogenesis is the definitive proof that the neuronal precursor cell population is intact, leading to the conclusion that external 
activation by immune cells is required for NSC proliferation. However, recent evidence suggests that the aged environment also fails to provide suitable support for CD4+ T cell activation (Lefebvre et al. 2012). When naïve CD4+ T cells were adoptively transferred into an aged microenvironment, they displayed delayed proliferation, priming, and transition to a follicular T helper cell phenotype. There are some reports that the HUCB MNC fraction is composed of phenotypically and functionally immature lymphocytes. Compared with the peripheral blood lymphocytes, HUCB contains a similar number of B lymphocytes but a reduced number of $\mathrm{T}$ lymphocytes (Harris et al.
1992). Moreover, the vast majority of HUCB-derived cytotoxic T cells show a high expression of CD45RA (a naive $\mathrm{T}$ cell marker) whereas most of the adult peripheral blood lymphocytes are CD45RO+ (an activated T cell marker) (Clement et al. 1990; D'Arena et al. 1998; Lucivero et al. 1996), which means that these HUCB-derived cells are more prone to initiating a Thelper cell tolerance-inducing response to antigen stimulation than adult cells (Barrios et al. 1996; Garderet et al. 1998; Thomson et al. 2000). These lower immunogenicity and stronger immunosuppressive effects could influence the brain environment, perhaps rendering it more conducive to neurogenesis.
Fig. 7 Representative images of Golgi stained CA1 pyramidal neurons in the sections from young rats treated with media (a) or HUCB MNC (b) and from old rats treated with media (c), HUCB MNC (d), CD14 (e), CD133 (f), CD4 (g), and CD8 (h). Scale bar $=50 \mu \mathrm{m}$
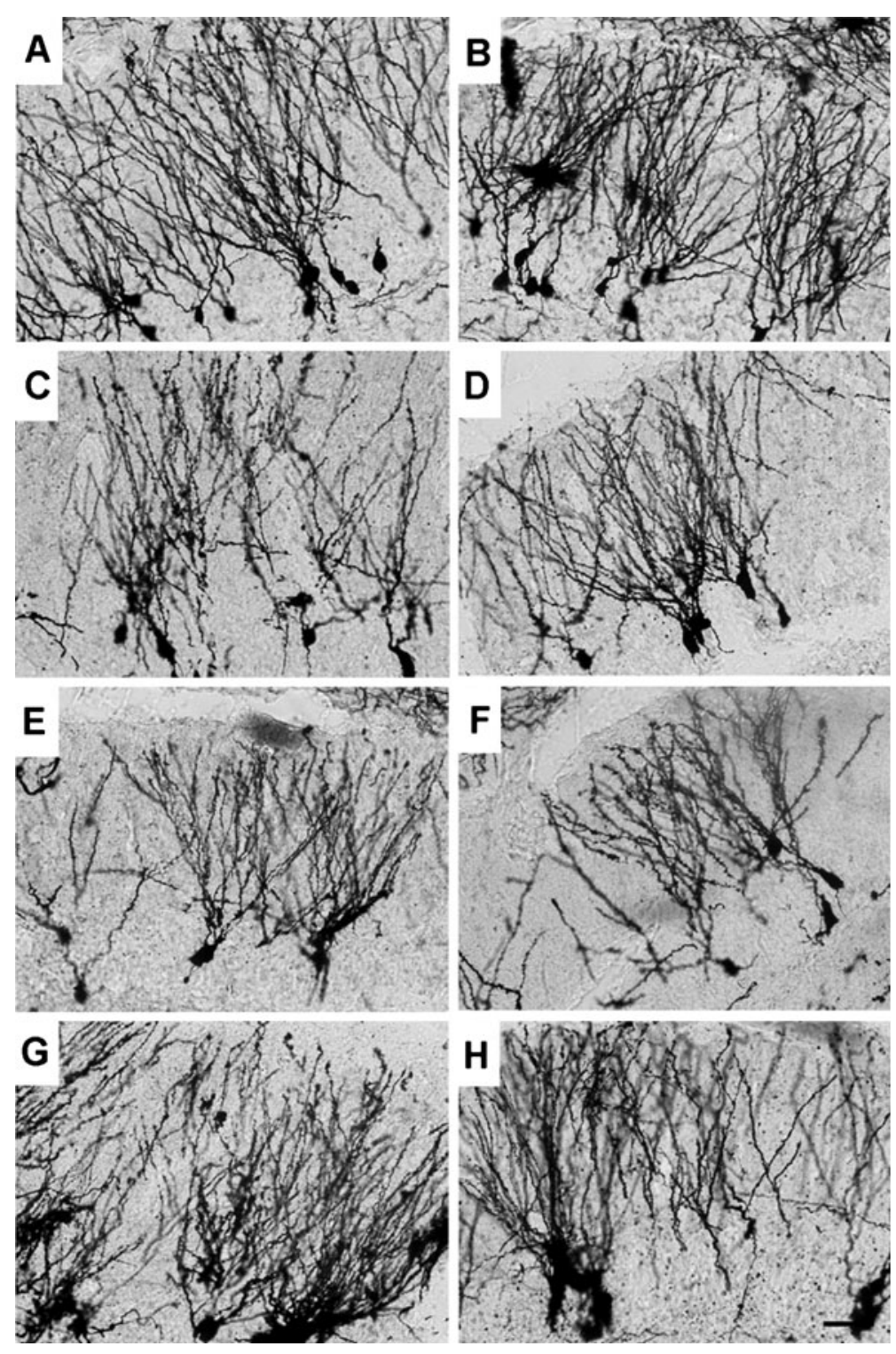


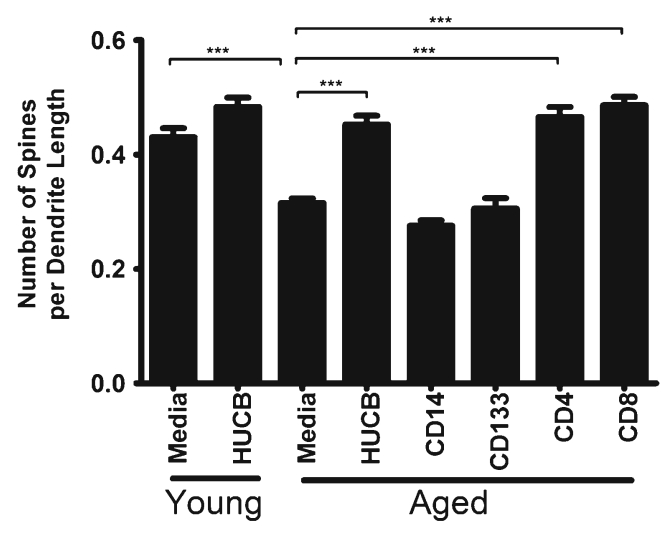

Fig. 8 Mean spine density (number/30 $\mu \mathrm{m}$ ) of dendrites in hippocampal CA1 pyramidal neurons. Aged rats treated with HUCB MNC, CD4, and CD8 cells had significantly more spines per length of dendrite than aged media-treated rats $(p<0.0001)$. However, MNC did not alter spine density in young rats when compared to the young media-treated rats

Several studies reported that there was a significant loss of both dendrites and dendritic spines with age
(Coleman and Flood 1987). Dendritic hypertrophy and a slower axonal transport rate was also reported (Tashiro and Komiya 1991). It may be that thick dendrites decreased with age leaving space for the thinner dendrites. In this study, we analyzed basal branches of CA1 pyramidal neurons as the smaller, granular cells of the DG have a distinctly different morphology and tend to be found as clumps of cells. Also, we analyzed dendritic spine density instead of the number of spines as it is easier, fast, and unequivocal (Horner and Arbuthnott 1991). It has been suggested recently that dendritic spines may be considered neuroprotectants through their ability to prevent calcium surges from spreading into the parent dendrite (Harris and Kater 1994). The results obtained demonstrated that the aged animals treated with CD4+ and CD8+ cells had significantly more spines per length of dendrites than aged animals treated with media. The other cells CD14+ and CD133+ did not show the same effect. This could suggest that the CD4+
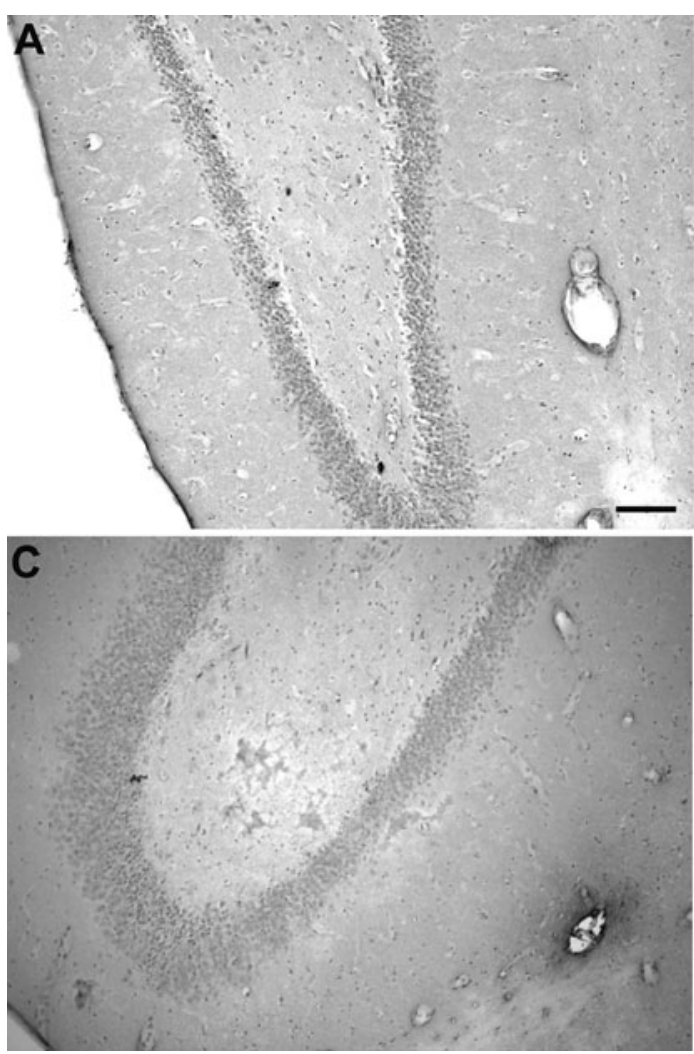

Fig. 9 BrdU+ cells in the DG 2 weeks after transplantation of CD4+ HUCB cells. Photomicrographs of BrdU+ cells (dark brown) in the sections from young rats treated with PBS (a), aged rats treated with $\mathrm{PBS}(\mathbf{b})$, and $\mathrm{CD} 4+$ cells $(\mathbf{c})$. d
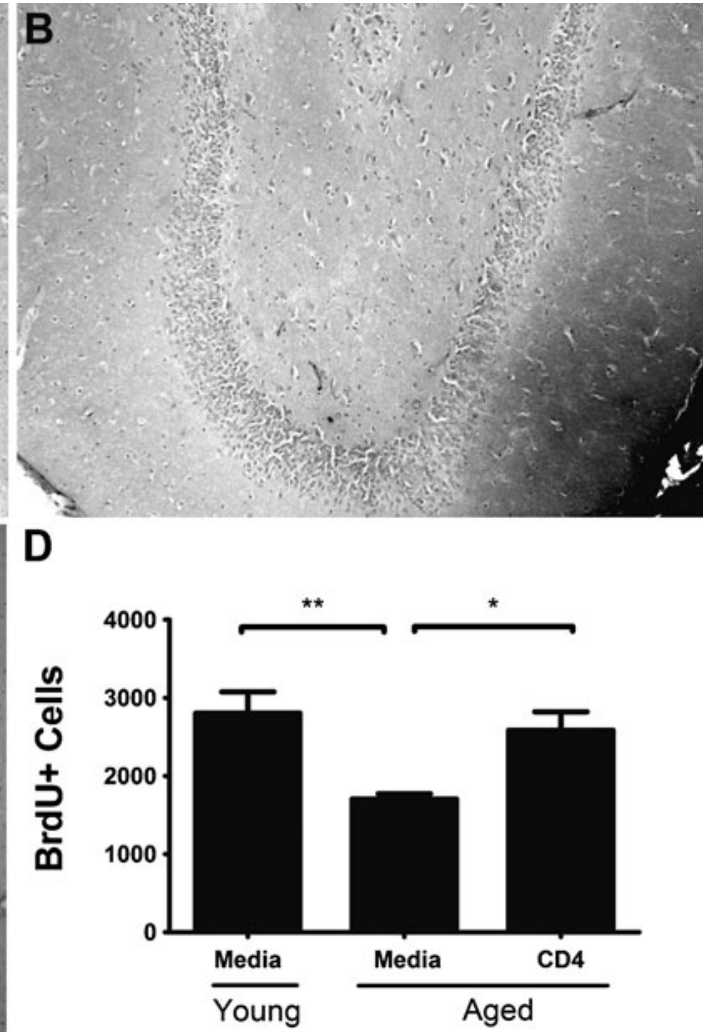

Representation of the quantitative analysis of BrdU+ cells in the DG. CD4+ T cell injection showed a significant increase $(p<$ $0.05)$ in hippocampal cell proliferation in the aged brain. Scale bar $=100 \mu \mathrm{m}$ 

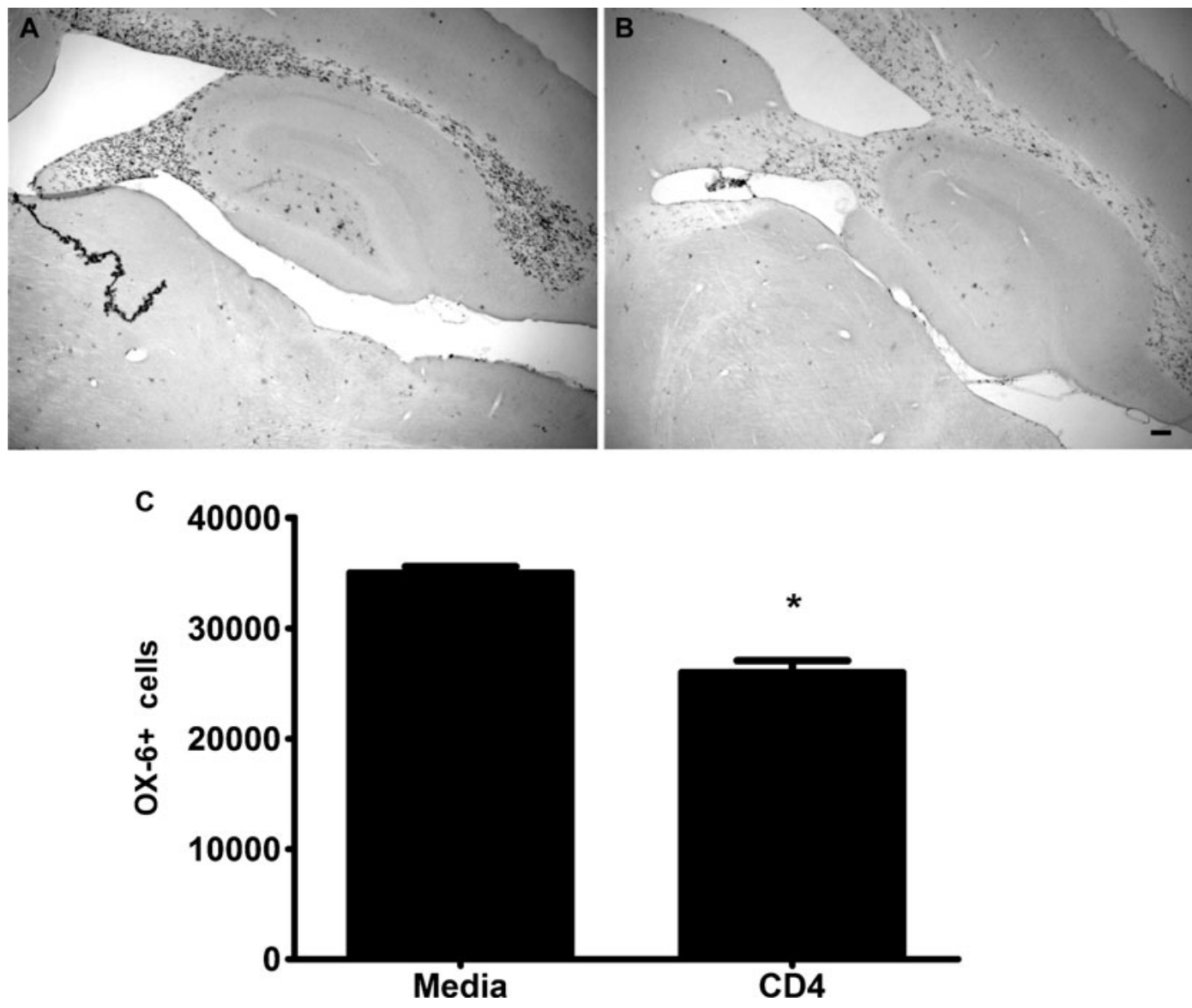

Fig. 10 HUCB CD4+ cells reduced microglial activation in aging rat brain. Representative micrograph of the hippocampus of rats treated with media (a) $(n=5)$ and CD4+ T cells (b) $(n=9)$ and immunostained with OX-6 to visualize activated microglia. c Quantitative stereological estimation of activated microglial densities in brain of PBS-treated aging rats or CD4+ cell-treated aging rats. Data shown are mean $\pm \mathrm{SD}$. A significant reduction in the number of OX-6+ cells was found in the DG of the aged rats treated with CD4+ cells $(p<0.001)$

important role in age-related reduction in neurogenesis (Ekdahl et al. 2003). Consistent with previous studies showing that HUCB MNCs reduce the number of activated microglia (Bachstetter et al. 2008; Vendrame et al. 2005), we did find that there was a significant decrease in the total number of OX-6+ microglia in the aged rats treated with $\mathrm{CD} 4+\mathrm{T}$ cells. It has been well documented that HUCB MNCs provide trophic support (Borlongan et al. 2004), decrease inflammation (Vendrame et al. 2005), and increase secretion of angiogenic factors in the brain (Taguchi et al. 2004). Studies have recently indicated that the aging-related decline in neurogenesis develops primarily from changes in the neurogenic microenvironment and in the factors that control the division of stem and progenitor cells (Doetsch 2003). HUCB cells may 
therefore exert their beneficial effects by providing trophic support or by shifting the microglial phenotype toward a neuroprotective one within the neurogenic niches. HUCB MNCs release neurotrophic factors including BDNF and vascular endothelial growth factor (VEGF) (Chen et al. 2010), both of which have been shown to play a critical role in adult hippocampal neurogenesis (Scharfman et al. 2005). BDNF has been identified as a strong candidate molecule regulating the key steps of adult SVZ neurogenesis as well (Bath et al. 2011). There is evidence that neurogenesis decreases in BDNF knockout mice (Linnarsson et al. 2000). Further, VEGF is believed to be the linking factor between neurogenesis and angiogenesis and there is a reduction of microvasculature and VEGF synthesis with aging (Shetty et al. 2005), which may contribute to the aging decline in cell genesis. It was further demonstrated that newly born cells in the DG are clustered in close proximity to blood vessels where VEGF expression is usually high, which suggests that the development of newborn cells is strongly influenced by local environmental factors (Palmer et al. 2000). Existing evidence demonstrates that both BDNF (Moalem et al. 2000) and VEGF (Khaibullina et al. 2004) receptors are expressed by $\mathrm{T}$ cells (Freeman et al. 1995). These T cell-mediated proneurogenic factors may potentiate the intrinsic capacity of newly born cells to respond to the mitotic stimuli provided by the neurogenic microenvironment. These trophic factors may also activate several regulatory signal transduction pathways for cell growth, differentiation, and survival, like PI3K/AKT, ERK1/2, and JAK/STAT3. It has been demonstrated that most of the neuronal progenitors during normal adult neurogenesis undergo apoptosis within their first days in life. Interestingly, unchallenged microglia engulf these apoptotic bodies of neural progenitors in the SGZ (Sierra et al. 2010). Here, we found a significant decrease in the number of activated OX-6+ microglia in the aged rats treated with $\mathrm{HUCB} \mathrm{CD} 4+$ cells. As such, HUCB cells may play an important regulatory role at the early stage of neurogenesis by reducing the number of activated microglia with a corresponding increase in the number of neuroprotective microglia.

The most intriguing finding of this study is that a single administration of HUCB T cells stimulates the proliferation of progenitor cells for at least 2 weeks after cell transplantation. In rodent stroke studies, HUCB cells have induced motor recovery and decreased lesion size in the brain even though few surviving HUCB cells were observed in the brain and few of these expressed neural markers (Chen et al. 2001). These observations suggest that replacement of lost neurons was not the primary mechanism underlying the cells' beneficial effects. Here, and in our previous reports (Bachstetter et al. 2008), our results showed that HUCB cells also had long-lasting effects on proliferation in the DG. In recent studies, using heterochronic parabiosis, age-dependent defects in stem cell niches were found to be systemically regulated and could be reversed by exposure to a young circulation (Conboy et al. 2005; Pishel et al. 2012; Villeda et al. 2011). There is also a marked increase in the myeloid cells in peripheral blood with a corresponding reduction in the number of both $\mathrm{T}$ and $\mathrm{B}$ cells, indicating a major contributory role of this diminished lymphocyte production and function to aging neurogenesis (Cho et al. 2008). It has also been reported that there is a significant reduction in the production of the CCL19 and CCL21 chemokines in the aged mouse spleen; these chemokines are believed to play a key role in the recruitment of B cells, T cells, and dendritic cells to the lymphoid organs (Lefebvre et al. 2012). We demonstrated that HUCB administration in a rat stroke model alters the ratio of $\mathrm{CD} 4+$ to $\mathrm{CD} 8+\mathrm{T}$ cells in the spleen and alters secretion of several cytokines from splenocytes, including TNF- $\alpha$, interferon gamma, and interleukin-10 (Vendrame et al. 2006). Thus, HUCB cells may produce their long-lasting effects on proliferation in the DG by directly or indirectly altering the systemic immune responses in aging rats. A better understanding of the cross-talk mechanism, mediated by the injected stem cells and host tissue, may provide insight into the long-lasting effects of HUCB T cells in aging hippocampus. Further studies are needed to better characterize the effects of HUCB T cells on the development of new cells in an old environment and identify the underlying changes in the host that appears to be sustained for long periods of time even after the HUCB cells are no longer present.

\section{Conclusion}

The current findings demonstrate that HUCB T cells stimulate proliferation of adult hippocampal neural stem cells and significantly enhance the density of dendritic spines in the aging brain back to the level 
observed in the young adult brain. Thus, it appears that administration of HUCB T cells would be beneficial in rejuvenating the microenvironment that leads to the decline in neurogenesis in the aging brain.

Acknowledgments This work was supported in part by grants from the National Institutes of Health, National Institute on Aging (R01 AG20927, AEW; P01 AG04418 PCB), and the Johnnie B. Byrd Alzheimer's Institute intramural research award (AEW). AEW is a consultant and PRS is a cofounder of Saneron CCEL Therapeutics, Inc., AEW and PRS are inventors on cord blood patents licensed to Saneron CCEL Therapeutics, Inc.

Open Access This article is distributed under the terms of the Creative Commons Attribution License which permits any use, distribution, and reproduction in any medium, provided the original author(s) and the source are credited.

\section{References}

Adlard PA et al (2011) Metal ionophore treatment restores dendritic spine density and synaptic protein levels in a mouse model of Alzheimer's disease. PLoS One 6(3): e17669

Antonchuk J, Sauvageau G, Humphries RK (2002) HOXB4induced expansion of adult hematopoietic stem cells ex vivo. Cell 109(1):39-45

Arien-Zakay H et al (2009) Neuroprotection by cord blood neural progenitors involves antioxidants, neurotrophic and angiogenic factors. Exp Neurol 216(1):83-94

Asahara T, Kawamoto A (2004) Endothelial progenitor cells for postnatal vasculogenesis. Am J Physiol Cell Physiol 287 (3):C572-C579

Bachstetter AD et al (2008) Peripheral injection of human umbilical cord blood stimulates neurogenesis in the aged rat brain. BMC Neurosci 9:22

Barrios C et al (1996) Neonatal and early life immune responses to various forms of vaccine antigens qualitatively differ from adult responses: predominance of a Th2-biased pattern which persists after adult boosting. Eur J Immunol 26 (7):1489-1496

Bath KG, Akins MR, Lee FS (2011) BDNF control of adult SVZ neurogenesis. Dev Psychobiol 54(6):578-589

Bodles AM, Barger SW (2004) Cytokines and the aging brainwhat we don't know might help us. Trends Neurosci 27 (10):621-626

Boltze J et al. (2012) Assessment of neuroprotective effects of human umbilical cord blood mononuclear cell subpopulations in vitro and in vivo. Cell Transplant 21(4):723-737

Borlongan CV et al (2004) Central nervous system entry of peripherally injected umbilical cord blood cells is not required for neuroprotection in stroke. Stroke 35(10):2385-2389

Burke SN, Barnes CA (2006) Neural plasticity in the ageing brain. Nat Rev Neurosci 7(1):30-40

Chapleau CA et al (2012) Hippocampal CA1 pyramidal neurons of Mecp2 mutant mice show a dendritic spine phenotype only in the presymptomatic stage. Neural Plast 2012:976164
Chen J et al (2001) Intravenous administration of human umbilical cord blood reduces behavioral deficits after stroke in rats. Stroke 32(11):2682-2688

Chen $\mathrm{N}$ et al (2010) Human umbilical cord blood cells have trophic effects on young and aging hippocampal neurons in vitro. Aging Dis 1(3):173-190

Cho RH, Sieburg HB, Muller-Sieburg CE (2008) A new mechanism for the aging of hematopoietic stem cells: aging changes the clonal composition of the stem cell compartment but not individual stem cells. Blood 111(12):5553-5561

Clement LT, Vink PE, Bradley GE (1990) Novel immunoregulatory functions of phenotypically distinct subpopulations of CD4+ cells in the human neonate. J Immunol 145(1):102-108

Coleman PD, Flood DG (1987) Neuron numbers and dendritic extent in normal aging and Alzheimer's disease. Neurobiol Aging 8(6):521-545

Conboy IM et al (2005) Rejuvenation of aged progenitor cells by exposure to a young systemic environment. Nature 433:760-764

D'Arena $G$ et al (1998) Flow cytometric characterization of human umbilical cord blood lymphocytes: immunophenotypic features. Haematologica 83(3):197-203

Doetsch F (2003) A niche for adult neural stem cells. Curr Opin Genet Dev 13(5):543-550

Ekdahl CT et al (2003) Inflammation is detrimental for neurogenesis in adult brain. Proc Natl Acad Sci U S A 100 (23):13632-13637

Emsley JG et al (2005) Adult neurogenesis and repair of the adult CNS with neural progenitors, precursors, and stem cells. Prog Neurobiol 75(5):321-341

Encinas JM et al (2011) Division-coupled astrocytic differentiation and age-related depletion of neural stem cells in the adult hippocampus. Cell Stem Cell 8(5):566-579

Freeman MR et al (1995) Peripheral blood T lymphocytes and lymphocytes infiltrating human cancers express vascular endothelial growth factor: a potential role for $\mathrm{T}$ cells in angiogenesis. Cancer Res 55(18):4140-4145

Gallagher M et al (1996) Hippocampal neurodegeneration in aging. Science 274(5287):484-485

Garbuzova-Davis S et al (2012) Multiple intravenous administrations of human umbilical cord blood cells benefit in a mouse model of ALS. PLoS One 7(2):e31254

Garderet L et al (1998) The umbilical cord blood alphabeta Tcell repertoire: characteristics of a polyclonal and naive but completely formed repertoire. Blood 91(1):340-346

Gemma C, Bachstetter AD, Bickford PC (2010) Neuronmicroglia dialogue and hippocampal neurogenesis in the aged brain. Aging Dis 1(3):232-244

Harris KM, Kater SB (1994) Dendritic spines: cellular specializations imparting both stability and flexibility to synaptic function. Annu Rev Neurosci 17:341-371

Harris DT et al (1992) Phenotypic and functional immaturity of human umbilical cord blood T lymphocytes. Proc Natl Acad Sci U S A 89(21):10006-10010

Hattiangady B, Shetty AK (2008) Aging does not alter the number or phenotype of putative stem/progenitor cells in the neurogenic region of the hippocampus. Neurobiol Aging 29(1):129-147

Horner CH, Arbuthnott E (1991) Methods of estimation of spine density - are spines evenly distributed throughout the dendritic field? J Anat 177:179-184 
Huang C et al. (2012) Entorhinal cortical neurons are the primary targets of FUS mislocalization and ubiquitin aggregation in FUS transgenic rats. Hum Mol Genet 21 (21):4602-4614

Khaibullina AA, Rosenstein JM, Krum JM (2004) Vascular endothelial growth factor promotes neurite maturation in primary CNS neuronal cultures. Brain Res Dev Brain Res 148(1):59-68

Kumar V et al (2005) Regulation of dendritic morphogenesis by Ras-PI3K-Akt-mTOR and Ras-MAPK signaling pathways. J Neurosci 25(49):11288-11299

Lee HJ et al (2012) Human umbilical cord blood-derived mesenchymal stem cells improve neuropathology and cognitive impairment in an Alzheimer's disease mouse model through modulation of neuroinflammation. Neurobiol Aging 33(3):588-602

Lefebvre JS et al. (2012) The aged microenvironment contributes to the age-related functional defects of CD4 T cells in mice. Aging Cell 11(5):732-740

Leonardo CC et al (2010) Administration of a sigma receptor agonist delays MCAO-induced neurodegeneration and white matter injury. Transl Stroke Res 1(2):135-145

Linnarsson S, Willson CA, Ernfors P (2000) Cell death in regenerating populations of neurons in BDNF mutant mice. Brain Res Mol Brain Res 75(1):61-69

Lucivero $G$ et al (1996) Functional characteristics of cord blood $\mathrm{T}$ lymphocytes after lectin and anti-CD3 stimulation. Differences in the way $\mathrm{T}$ cells express activation molecules and proliferate. Int J Clin Lab Res 26(4):255-261

Maslov AY et al (2004) Neural stem cell detection, characterization, and age-related changes in the subventricular zone of mice. J Neurosci 24(7):1726-1733

Moalem G et al (2000) Production of neurotrophins by activated $\mathrm{T}$ cells: implications for neuroprotective autoimmunity. $\mathrm{J}$ Autoimmun 15(3):331-345

Morgenstern NA, Lombardi G, Schinder AF (2008) Newborn granule cells in the ageing dentate gyrus. J Physiol 586 (16):3751-3757

Newcomb JD et al (2006) Timing of cord blood treatment after experimental stroke determines therapeutic efficacy. Cell Transplant 15(3):213-223

Palmer TD, Willhoite AR, Gage FH (2000) Vascular niche for adult hippocampal neurogenesis. J Comp Neurol 425 (4):479-494

Pishel I et al (2012) Accelerated aging versus rejuvenation of the immune system in heterochronic parabiosis. Rejuven. Res. 2:239-248

Romero JM et al (2002) Diffusion MR imaging of acute ischemic stroke. Neuroimaging Clin N Am 12(1):35-53
Rowe DD et al (2012). Human unbilical cord blood cells protect oligodendrocytes from brain ischemia through Akt signal transduction. J Biol Chem 287(6):4177-4187

Scharfman $\mathrm{H}$ et al (2005) Increased neurogenesis and the ectopic granule cells after intrahippocampal BDNF infusion in adult rats. Exp Neurol 192(2):348-356

Shetty AK, Hattiangady B, Shetty GA (2005) Stem/progenitor cell proliferation factors FGF-2, IGF-1, and VEGF exhibit early decline during the course of aging in the hippocampus: role of astrocytes. Glia 51(3):173-186

Sierra A et al (2010) Microglia shape adult hippocampal neurogenesis through apoptosis-coupled phagocytosis. Cell Stem Cell 7(4):483-495

Taguchi A et al (2004) Administration of CD34+ cells after stroke enhances neurogenesis via angiogenesis in a mouse model. J Clin Invest 114(3):330-338

Tashiro T, Komiya Y (1991) Maturation and aging of the axonal cytoskeleton: biochemical analysis of transported tubulin. $\mathbf{J}$ Neurosci Res 30(1):192-200

Thomson BG et al (2000) Analysis of engraftment, graftversus-host disease, and immune recovery following unrelated donor cord blood transplantation. Blood 96 (8):2703-2711

Vendrame $M$ et al (2004) Infusion of human umbilical cord blood cells in a rat model of stroke dose-dependently rescues behavioral deficits and reduces infarct volume. Stroke 35(10):2390-2395

Vendrame $\mathrm{M}$ et al (2005) Anti-inflammatory effects of human cord blood cells in a rat model of stroke. Stem Cells Dev 14 (5):595-604

Vendrame $\mathrm{M}$ et al (2006) Cord blood rescues stroke-induced changes in splenocyte phenotype and function. Exp Neurol 199(1):191-200

Villeda SA et al (2011) The ageing systemic lilieu negatively regulates neurogenesis and cognitive function. Nature 477:90-94

West MJ, Gundersen HJ (1990) Unbiased stereological estimation of the number of neurons in the human hippocampus. $\mathrm{J}$ Comp Neurol 296(1):1-22

Williams RW, Rakic P (1988) Three-dimensional counting: an accurate and direct method to estimate numbers of cells in sectioned material. J Comp Neurol 278(3):344352

Wolf SA et al (2009) CD4-positive T lymphocytes provide a neuroimmunological link in the control of adult hippocampal neurogenesis. J Immunol 182(7):3979-3984

$\mathrm{Ziv} Y$ et al (2006) Immune cells contribute to the maintenance of neurogenesis and spatial learning abilities in adulthood. Nat Neurosci 9(2):268-275 